\title{
Obesity: lessons from evolution and the environment
}

Citation for published version (APA):

Heitmann, B. L., Westerterp, K. R., Loos, R. J., Sorensen, T. I., O' Dea, K., Mc Lean, P., Jensen, T. K., Eisenmann, J., Speakman, J. R., Simpson, S. J., Reed, D. R., \& Westerterp-Plantenga, M. S. (2012). Obesity: lessons from evolution and the environment. Obesity Reviews, 13(10), 910-922. https://doi.org/10.1111/j.1467-789X.2012.01007.x

Document status and date:

Published: 01/10/2012

DOI:

10.1111/j.1467-789X.2012.01007.x

Document Version:

Publisher's PDF, also known as Version of record

Document license:

Taverne

Please check the document version of this publication:

- A submitted manuscript is the version of the article upon submission and before peer-review. There can be important differences between the submitted version and the official published version of record.

People interested in the research are advised to contact the author for the final version of the publication, or visit the DOI to the publisher's website.

- The final author version and the galley proof are versions of the publication after peer review.

- The final published version features the final layout of the paper including the volume, issue and page numbers.

Link to publication

\footnotetext{
General rights rights.

- You may freely distribute the URL identifying the publication in the public portal. please follow below link for the End User Agreement:

www.umlib.nl/taverne-license

Take down policy

If you believe that this document breaches copyright please contact us at:

repository@maastrichtuniversity.nl

providing details and we will investigate your claim.
}

Copyright and moral rights for the publications made accessible in the public portal are retained by the authors and/or other copyright owners and it is a condition of accessing publications that users recognise and abide by the legal requirements associated with these

- Users may download and print one copy of any publication from the public portal for the purpose of private study or research.

- You may not further distribute the material or use it for any profit-making activity or commercial gain

If the publication is distributed under the terms of Article $25 \mathrm{fa}$ of the Dutch Copyright Act, indicated by the "Taverne" license above, 


\title{
Stock Conference report/Etiology and Pathophysiology
}

\section{Obesity: lessons from evolution and the environment}

\author{
B. L. Heitmann', K. R. Westerterp², R. J. F. Loos ${ }^{3}$, T. I. A. Sørensen ${ }^{1,4}$, K. O'Dea ${ }^{5}$, P. McLean', \\ T. K. Jensen ${ }^{7}$, J. Eisenmann ${ }^{8}$, J. R. Speakman ${ }^{9,10}$, S. J. Simpson ${ }^{11}$, D. R. Reed ${ }^{12}$ and \\ M. S. Westerterp-Plantenga ${ }^{2}$
}

${ }^{1}$ Institute of Preventive Medicine, Centre for Health and Society, Copenhagen University Hospitals, Copenhagen, Denmark;

²Department of Human Biology, NUTRIM, FHML, MUMC, Maastricht University, Maastricht, The Netherlands; ${ }^{3}$ Charles R. Bronfman Institute for Personalized Medicine Mount Sinai School of Medicine, New York, NY, USA; ${ }^{4}$ Novo Nordisk Foundation Center for Basic Metabolic Research, University of Copenhagen, Copenhagen, Denmark;

${ }^{5}$ Sansom Institute for Health Research, University of South Australia, Adelaide, South Australia, Australia; ${ }^{6}$ Center for Human Nutrition, Anschutz Medical Campus, University of Colorado, Denver, CO, USA; ${ }^{7}$ Department of Environmental Medicine, University of Southern Denmark, Odense, Denmark; ${ }^{8}$ The Healthy Weight Center, Helen DeVos Children's Hospital, Grand Rapids, MI, USA; ${ }^{9}$ Key State Laboratory of Molecular and Developmental Biology, Institute of Genetics and Developmental Biology, Chinese Academy of Sciences, Beijing, China; ${ }^{10}$ Institute of Biological and Environmental Sciences, University of Aberdeen, Aberdeen, Scotland, UK; ${ }^{11}$ School of Biological Sciences and the Charles Perkins Centre for Obesity, Diabetes and Cardiovascular Disease, The University of Sydney, Sydney, Australia;

${ }^{12}$ Monell Chemical Senses Center, Philadelphia, PA, USA

Received 14 February 2012; revised 11 April 2012; accepted 23 April 2012

Address for correspondence: Professor Dr. MS Westerterp-Plantenga, Maastricht University, Department of Human Biology, PO Box 616, NL-6200MD Maastricht, The Netherlands.

E-mail: m.westerterp@maastrichtuniversity.nl

\section{Summary}

The 9th Stock Conference acknowledged the complex background of genetic, cultural, environmental and evolutionary factors of obesity. Gene-environment interactions underlie the flexibility in body-weight and body-fat regulation, illustrated by the hunter-gatherers' feast and famine lifestyle, the variation in physical activity over the lifespan being highest at reproductive age, the variation in energy intake through 'eating in the absence of hunger', while running the risk of exceeding the capacity of triacylglyceride storage, leading to lipotoxicity and metabolic problems. Perinatal metabolic programming for obesity via epigenetic changes in response to a 'Western diet' results in production of lipid-poor milk and metabolically efficient pups, contributing to the perpetuation of obesity throughout generations. Evolutionary insight from comparative physiology and ecology indicates that over generations activity-induced energy expenditure has remained the same compared to wild mammals, that energy balance might be dependant on protein balance, while the function of taste changed from detection of poison or energy to social drinking and social behaviour. At present, the impact of assortative mating on obesity prevalence is unambiguously positive. The complexity that appeared can only be fully appreciated by setting the data into the context of our evolutionary history.

Keywords: Comparative ecology and physiology, energy storage, perinatal programming, stock conference.

obesity reviews (2012) 13, 910-922 


\section{Introduction}

Although varying in prevalence, overweight and obesity have become evident and intrusive in all societies worldwide, a development that has taken less than half a century. This dramatic increase is often used as the main argument for why obesity must be a strictly environmentally indicated condition, caused by too much food and too little exercise. Whereas it is well established that rapid globalization of the westernized lifestyle is going alongside this obesity epidemic, including the proposal of a direct link between globalization and obesity (1), we still do not fully understand the reasons for the current epidemic of obesity. It is clear that the etiology is a complex mixture of genetic, environmental, psychosocial, cultural and cognitive influences. The recent discovery of robust obesity-susceptibility loci has increased the interest to examine whether lifestyle can attenuate or exacerbate the association between a genetic locus and obesity susceptibility. From an evolutionary point of view, we still possess the genetic heritage of prehistoric man, but new research points towards a possibility of changing gene function without influencing genomic sequences ('epigenetics'), and thus allowing for changes in susceptibility to obesity within one and between two generations.

The 9th Stock Conference, hosted by the International Association for the Study of Obesity (IASO), was held in Budapest, Hungary, from November 10 to 13, 2011, and co-chaired by Berit Heitmann, Klaas and Margriet Westerterp. The focus was on identifying the lessons that could be learned from evolution and the responses to the environment. Already more than 10 years ago, it was recognized by the American Medical Association that obesity is a complex, multifactorial condition in which excess body fat may put a person at health risk. National data indicate that the prevalence of obesity in the United States is increasing in children and adults (2). Although its etiology is not firmly established, genetic, metabolic, biochemical, cultural and psychosocial factors contribute to obesity. Some individuals may become overweight or obese partly because they have a genetic or biological predisposition to gain weight readily. In addition, the increasing prevalence of overweight and obesity reflects changes in society and behaviours over the past 20-30 years (2). Our aim was to acknowledge that the determinants include a complex mix of genetic, cultural, environmental and evolutionary factors. In total, 12 distinguished speakers and 28 attendees were brought together to discuss how in the context of genes and their interaction with physical activity, dietary intake, sleep and circadian rhythm, our evolutionary history and the changing environment have contributed to the current obesity epidemic. Insights were gained not only from Western experiences among children and adults in differing social contexts, but also from indigenous hunter-gatherer populations such as Australian Aborigines.
In her introductory comments, Berit Heitmann suggested that such functional changes may come about as a consequence of changes in nutrient intake or in response to a changing environment that includes an enhanced exposure to pollutants, pesticides and other chemicals. Our current understanding that the obesity epidemic is the consequence of disturbances in energy balance is refined by new research showing that changes in energy and nutrient intakes, rather than decreased energy expenditure, may have fuelled the epidemic. Furthermore, new possible etiological players including sleep and circadian rhythm, viruses, changes in the metagenome and temperature changes have been identified.

Gene-environment interactions on energy expenditure, energy intake and energy storage were reviewed by $R u t h$ Loos. While lifestyle changes during the past few decades have had a major role in the rise in obesity prevalence worldwide, there is convincing evidence that our genome, which has remained largely unchanged for generations, contributes to obesity susceptibility. After all, not everyone who is exposed to the present-day obesogenic environment is overweight or obese. This inter-individual variation in obesity susceptibility in a population that is exposed to a uniform environment can, at least in part, be attributed to a genetic predisposition to gain weight. Indeed, obesity arises through the joint actions of multiple genetic and environmental factors that not only act additively, but also interact with each other. A classical example of such interaction is that of the Pima Indians. More than two-thirds $(69 \%)$ of the Pima Indians who live in the obesogenic environment of Arizona are obese, compared to $\sim 30 \%$ of the white Americans who live in the same environment (3). However, only $13 \%$ of the Pima Indians who live in the restrictive environment of the remote Mexican Sierra Madre Mountains are obese (3). These observations suggest that Pima Indians' genetic make-up makes them overly sensitive to environmental influences in relation to obesity risk. Further observations have been reported in well-controlled lifestyle intervention studies with twins (4-6). For example, 12 monozygotic twin pairs, who were overfed with $1,000 \mathrm{kcal} \mathrm{d}^{-1}$ for $100 \mathrm{~d}$, gained on average $8.1 \mathrm{~kg}$ with a range of $4-12 \mathrm{~kg}$. Most interestingly, while there was large variation in weight gain between pairs, the variation was three times less within the pairs (4). This supports the notion that the response to these changes depends on an individual's genetic predisposition. Similar results were observed in twin studies that examined the influence of exercise (5) and diet (6) on weight loss.

So far, few studies have reported convincing interactions between lifestyle and genetic loci on obesity risk. For instance, a growing number of studies report that physical activity attenuates the association between variants in the FTO locus and obesity-related traits (7), including a largescale meta-analysis that indicated that physical activity significantly attenuated the effect of FTO variants on obesity 
risk and body mass index (BMI) by approximately $30 \%$ in adults (8). The physiological mechanisms through which physical activity reduces $F T O$ effects remain to be elucidated. The first intron of FTO might be sensitive to epigenetic effects, as variants in this region have been shown to influence its methylation capability $(9,10)$.

In another recent study that used a genetic score that summed the BMI-increasing allele across 12 established obesity-susceptibility loci (11), the increase in BMI was $\sim 40 \%$ more pronounced in sedentary individuals than in physically active individuals. Similar interaction effects were observed for the risk of obesity.

Joosen and Westerterp assessed the magnitude of the genetic contribution to the range of activity-induced energy expenditure (AEE), by measuring this component in the confined and standardized environment of a respiration chamber, which is an indicator of free-living AEE (12-14). The separate genetic and environmental variance components of AEE were analysed with a classic twin design, showing that a genetic influence explained the largest part of the variation in AEE in daily life, whereas AEE was influenced by environment only within the confined area of the respiration chamber (15). So far, this is one of the few studies that quantify the genetic contribution to variation in AEE, using gold standard techniques like doubly labelled water and validated triaxial accelerometers for movement registration.

Taken together, findings on gene-physical activity interactions present an important public health message as they challenge the deterministic view held by many than the genetic susceptibility to obesity is unmodifiable. In contrast, Loos suggested that the genetic susceptibility can be overcome, at least in part, by adopting a physically active lifestyle in order to prevent overweight and obesity.

Margriet Westerterp-Plantenga reviewed geneenvironment interactions in relation to food intake. She emphasized that humans appear to regulate energy balance on a weekly rather than daily basis (16). While energy expenditure, which determines energy requirement, is continuous, energy intake is discontinuous, and requires a mechanism for tuning it to energy expenditure. Hunger and satiety play a role (17), and changes in gut hormone and glucose concentrations have been suggested to act as biomarkers for nutrient-related satiety (18). However, Westerterp-Plantenga and colleagues have shown that these mechanisms show a large variability, as over-eating or under-eating relative to the energy requirement often occurs. This flexibility includes insensitivity to gut-peptide signals especially in overweight and obese individuals $(19,20)$, and sensitivity to modulators such as circadian rhythm and sleep $(21,22)$, ambient temperature $(23,24)$ and hypobaric hypoxia (25).

Over-eating, relative to energy requirement, occurs as eating in the absence of hunger, and is driven by anticipated reward $(26,27)$. Reward is defined as 'liking' and 'wanting', expressing the hedonic value of food or food preference, respectively the motivation to obtain food. Task-related signalling (TRS) for liking and wanting is represented in the brain in overlapping brain areas such as in the thalamus and visual cortex (28), and in separate brain areas, namely in the caudatus for wanting postprandially, and in the insula for liking (28). Before a meal, a high brain activation for wanting TRS is present in the frontal cortex, orbitofrontal cortex and putamen. After the meal, putamen activity decreases. This decrease is strongly present in successful dietary restraint subjects, not only related to wanting TRS but also to liking TRS, but fails to take place under stress, which is related to stress-induced over-eating for reward $(27,29)$.

On the other hand, post-meal wanting TRS in the hypothalamus, implying inhibition of eating, is inversely related to hunger and BMI, thereby facilitating over-eating in the overweight and obese individuals. This phenomenon points towards reward deficiency driven over-eating in those subjects (28).

The genetic contribution to the variation in energy intake and its flexibility appears from studies on geneenvironment interactions that are present for pre- to postprandial perceived hunger, satiety, and for orexigenic and anorexigenic hormone concentrations.

Associations with the polymorphisms in LEPR, NPY2R and GHRL have been shown (30). Dietary restraint and disinhibition has been associated with polymorphisms in GHSR (30). In addition, postprandial responses in hunger and satiety were associated with the rs9939609 nucleotide polymorphism in FTO (31), while epistatic interactions involved DNMT3B and LEPR (31).

Finally, polymorphisms of CLOCK, TIMELESS, ARNTL, PROK2 and CSNK2A related to circadian rhythm and sleep appeared to be associated with overweight and obesity $(32,33)$. Taken together, WesterterpPlantenga stated that gene-environment interactions are present for pre- to postprandial changes in hunger, satiety, orexigenic and anorexigenic hormones, circadian alignment of food intake, and dietary restraint, indicating a variation for the ability of eating in the absence of hunger, either to survive fluctuations, including limitations in food availability, or to become obese.

Thorkild Sørensen reviewed energy storage related to gene-environment interactions. Triacylglyceride (TAG) is a perfect compound for energy storage - it is energy dense and biologically inert. Sørensen stated that the body has a fine machinery to store it, mobilize it and to use its energy content $(34,35)$. When the available space, as determined by the number and maximum size of normally functioning adipocytes, is filled, ectopic accumulation occurs. When total limits of storage capacity are exceeded and there is no need of the excess fatty acids as a current energy source, 
fatty acids accumulate in the blood, which appear to be toxic (lipotoxicity) and lead to metabolic problems $(34,35)$. Storage capacity and distribution of adipose stores within the body varies between populations (e.g. Asians vs. nonAsians), individuals within populations, within individuals over time (age) and across generations. The capacity to store energy may be determined by genes, early life experience, even before conception, and current environmental exposures. It makes little sense to measure how much TAG is stored without knowing the residual storage capacity. For instance, for a given BMI, Asians have a higher body fat percentage, abdominal obesity, a higher intramyocellular lipid and/or a higher liver fat content compared to Caucasians. This contributes to a higher predisposition to insulin resistance at a lower BMI than Caucasians (36). Sørensen advocates that the approach of obesity should be directed towards assessment of the adverse effects of fatty acids accumulating in the blood, leading to lipotoxicity and metabolic problems $(34,35)$. Measuring how much TAG is stored is insufficient if one does not know the residual storage capacity.

Karen O'Dea reviewed the insight that could be gained on the development of obesity from studies on prehistoric variability in body weight. The flexibility in energy balance as being outlined above was clearly used by the humans living as hunter-gatherers for most of their history whether we date that from the emergence of modern man ( 100,000 years BP) or from the emergence of Homo habilis, our tool-making ancestor (1.8-2 million years ВР). O'Dea argues that it is to that ancestral diet and lifestyle that humans are primarily genetically adapted. The few remaining hunter-gatherer societies that survived into the 20th century provide a window into that past lifestyle and give insights into its impact on health. In the most remote parts of Australia, small groups of Aborigines continued to live a nomadic lifestyle until 50-60 years ago. Research (37) indicates that they were very lean, with no evidence of the chronic diseases (central obesity, type 2 diabetes, vascular diseases and kidney failure) that occur in epidemic proportions in contemporary westernized Aboriginal communities in Australia today.

In 1982, O'Dea studied the impact of 7-week reversion to hunter-gatherer lifestyle on health in a group of middleaged, diabetic Aboriginal people from a remote community in northwest Australia, who had retained the knowledge and ability to 'live off the land'. Seven weeks of this traditional hunter-gatherer lifestyle had a profound therapeutic benefit, greatly reducing all of the metabolic abnormalities of diabetes and vascular disease-risk factors (38). Animal foods made the greatest contribution to the diet. Food was consumed when it was available. Everything edible was consumed, and people exhibited a capacity to gorge, eating $2-3 \mathrm{~kg}$ of lean meat or fish if available, but eating very little on unsuccessful days ('feast-and-famine').
Significantly, the most highly prized foods were the few that were energy dense: fat depots, bone marrow, organ meats such as brain and liver, fatty insects and honey. Such foods were only available seasonally and/or in small quantities, their procurement was energy intensive, and they needed to be shared with others.

The survival strategies of hunter-gatherers were to maximize energy input (capacity to gorge, preference for energy-dense foods) and minimize energy output (avoid unnecessary physical activity) (38). Throughout human history, food procurement has involved hard physical work, and food shortages were common; never before in human history has there been continual food abundance. Thus, humans have developed many biological adaptations to hunger, but not for over-consumption. Finally, O'Dea conveyed the insight that from a hunter-gatherer perspective the modern Western diet and lifestyle would seem to be ideal for survival: an abundance of energy-dense foods high in fat and sugar, readily available at low cost, and for minimal effort. The unintended consequence is the serious epidemic of obesity, type 2 diabetes and related conditions across the world.

Paul Maclean addressed the role of perinatal metabolic programming in perpetuating the propensity to become obese from one generation to the next, beyond the inherited genetic predisposition for obesity (39). Maternal malnutrition, both over- and under-nutrition, can impact the development of homeostatic systems that control energy balance and adiposity (40-44). Programming occurs as the maternal environment imposed upon the developing fetus and neonate induces epigenetic changes that may include DNA methylation, genetic imprinting and histone modifications. The programming leads to alterations in gene expression having lasting consequences on growth rates, adaptations to metabolic stress and the susceptibility to metabolic disease.

Diets high in fat and simple sugars (i.e. Western diet) that promote maternal overfeeding during gestation and lactation lead to offspring that exhibit hyperphagia, accelerated growth rates and a propensity to become obese. In addition, these effects may be accentuated with maternal obesity $(41,44-46)$. Prenatal stress yields the same consequences in offspring $(44,45)$, while a transient period of exercise after weaning prevents them $(47,48)$. Maternal obesity, however, imposes distinct developmental challenges during the post-natal period, which can even override a genetic disposition for leanness (41).

Obese women are known to have a difficult time breastfeeding and their offspring have problems maintaining adequate neonatal growth $(49,50)$. A similar impairment with obesity is observed in mice on a Western diet. Obese dams consuming a Western diet produce lipid-poor milk compared to lean dams on the same diet (46). This effect of obesity on lactation performance has two consequences in 
their offspring. First, their pups adapt to energy restriction by becoming more metabolically efficient and slowing their growth rate (46), which may predispose them to 'catch-up' growth favouring fat deposition later in development. Second, their pups oxidize more protein and carbohydrate to produce the energy for growth (46), which may inadvertently program an inability to oxidize fat later in life. Even so, it appears that perinatal metabolic programming provides a distinct path to obesity in early life. These epigenetic events may exacerbate an underlying genetic disposition or yield the same end where no genetic disposition exists. Together, Maclean stated, the genetic and epigenetic consequences are likely to contribute to the perpetuation of obesity from generation to generation, so long as the obesogenic pressures persist.

Tina Kold Jensen reviewed the role of endocrine disruptors to the current epidemic of obesity. Developmental exposure to environmental pollutants with hormonal activity, whose production and use has increased simultaneously with the rise in these conditions, may play a role in the obesity epidemic (51,52). These endocrine disrupting chemicals (EDCs) have been linked to a growing list of adverse health consequences and those that are oestrogenic or anti-androgenic are most plausibly linked to metabolic changes (53). EDCs are widely detected as pollutants in food because of contamination of food processing and packaging materials and/or bioaccumulation in the food chain (54). They include bisphenol A (BPA), phthalates and perfluorinated chemicals (perfluorinated alkylated substance [PFAS]) (55-58).

These chemicals are widely used and can be measured in urine and serum of almost all humans both adults and children. PFASs are fluorinated compounds that are water and oil resistant and used in a broad range of products, e.g. in waterproofing and protective coatings of clothes, furniture, and in floor polish, paints, non-stick cookware and food packaging $(58,59)$. PFASs are worldwide contaminants of the environment, wildlife, food and drinking water (60). A newly published study found an association between maternal PFAS measured during pregnancy and increased body weight at 20 years of age in the female offspring (61). BPA is a key monomer in production of polycarbonate plastic and epoxy resins (56). It has been found to leak from heated plastic baby bottles into the formula milk and from can lining. Concern has been raised by published studies reporting a relationship between fetal exposure to 'low doses' of BPA and obesity at puberty in experimental studies in laboratory animals (62). A cross-sectional American study found association between BPA levels and obesity and metabolic syndrome-related conditions (63). Phthalates are ubiquitous industrial chemicals used as plasticizers, solvents and lubricants in manufacturing of consumer products such as children's toys, medical equipment, cosmetics, food packaging and building materials. Only few human (cross- sectional) studies have evaluated phthalates and obesityrelated outcomes. These reported positive correlations between phthalate metabolites, waist circumference and insulin resistance among adult men $(57,64)$.

Most EDCs accumulate in fat tissue (56), which is of great concern as body fat is not merely a depot for storage of triglycerides, but also an endocrine gland crucially involved in energy regulation $(52,55)$. If exposure occurs in early life stages (fetal and/or childhood), EDCs might interfere with the programming of endocrine-signalling pathways established during vulnerable periods of life. In addition, Jensen stated that exposure to EDCs has been associated with obesity-related comorbidities $(52,54,55)$.

Klaas Westerterp and John Speakmann reviewed the changes in physical AEE over the lifespan. Physical AEE gradually increases from early age to adulthood and decrease again in old age. Westerterp and colleagues showed the development of physical AEE over the lifespan by expressing it as a fraction of total energy expenditure. At 1 year of age, when children start to walk, about $20 \%$ of daily energy expenditure is accounted for by physical activity. The fraction increases to adult values of about $33 \%$ at age 15 years soon after reproductive age is reached (65). After 15 years of age, activity energy expenditure remains on average at a constant level during adulthood and then gradually decreases after age 50 years (66). At age 90 years, humans are spending again $20 \%$ of daily energy expenditure for physical activity identical to the age of 1 year when they started to walk. Thus, it seems that physical AEE is highest during the reproductive years. Furthermore, Westerterp showed that once individuals are obese, they have higher daily energy expenditure because of a higher maintenance requirement for their larger body size. Then, activity energy expenditure is mainly affected by body mass. Body movement but not activity energy expenditure is reduced in the obese $(67,68)$.

The changes in physical activity energy expenditure as we age are inferred from a cross-sectional study of daily energy demands and its components seem to start at around the age of $52(66)$. This time also corresponds to the commencement of a number of other changes. Fat-free mass (FFM) also starts to decline and this leads in part to a decrease in basal energy expenditure, although many studies have shown that the decline in basal metabolic rate cannot be completely accounted for by changes in body composition alone, pointing to an independent age-related decrease. The progressive loss of muscle mass with age (sarcopenia) is one of the most significant problems of ageing, and in later life is one of the key factors that influence mobility and dependence. Looking at the coincidence of the cross-sectional patterns of AEE and FFM with age, it would be tempting to speculate that these events are causally linked. That is high levels of activity (reflected in AEE) may protect from FFM loss. However, this seems not 
to be the case. Statistically controlling for the effect of age reveals there is no association between age-specific activity levels and FFM (66). More significantly, activity intervention studies in the aged do not significantly preserve FFM and prevent its progressive loss - although resistancetraining interventions can prevent muscle loss. Speakmann states that it would appear that rather than the amount of FFM being a significant factor driving age-related changes in activity that a much more important issue is muscle quality.

Joey Eisenmann discussed the role of biocultural changes during childhood and adolescence, related to the variation in physical activity. In general, children enjoy engaging in physical movement, but, as Eisenmann and colleagues have shown, there is a clear age-related decline in habitual physical activity expressed as time spent in moderate-to-vigorous physical activity particularly during adolescence (69). Several factors influence the development of the physical activity phenotype during childhood and adolescence, and it needs to be recognized that children and adolescents are involved in the 'business' of growing up (70). 'Growing up' is a biocultural experience, which involves interactions with the psychosocial-behavioural aspects of development. The ontogeny of physical activity during childhood and adolescence is a complex multifactorial phenotype influenced directly and indirectly by the multiple demands of 'growing up' including genetics, prenatal exposures and perhaps epigenetics, and a myriad of postnatal factors that include biological, psychological and social factors, as well as the physical environment, that act independently and with each other as a child grows up (69-74). To predict which children are physically active and remain active throughout childhood and adolescence has not been successfully demonstrated in the literature (69-74). Eisenmann suggested that in order to achieve this aim, a comprehensive multivariate, multidisciplinary longitudinal model is necessary that considers the biocultural approach. The period of adolescence seems to be especially a period of decline in physical activity that needs to be better understood from a biopsycho-sociocultural perspective. Yet, on the other hand, Westerterp and colleagues have explained that the increase in body size results in the gradual increase of activity energy expenditure from $20 \%$ of total energy expenditure to the adult value of about $33 \%$ after 15 years of age, shortly after reproductive age is reached, and the physical AEE is at its highest.

The potential effect of changes in sleep duration during puberty on the development of obesity was addressed by Margriet Westerterp-Plantenga. During puberty, BMI increases, and sleep duration decreases, in a related way, independent of possible confounders, as was shown by Westerterp-Plantenga and colleagues (75). In addition, they showed that the influence of polymorphisms of the FTO gene changes during puberty (76). The FTO A allele is associated with higher BMI, fat mass index and leptin concentrations from 12 years of age, while the strength of the associations decreases at age 13-14 years, and becomes stronger at age 17 years. The decreased association is presumably caused by the dominating endocrinological changes at mid-puberty (76). In boys and girls during puberty, factors independent of fat mass become (transiently) more important in the regulation of plasma leptin concentrations. In girls, leptin acts as a permissive factor for the onset of puberty, while, in boys, leptin has a different timing and function (77).

The rewiring of the hypothalamus during puberty may help to explain the relationship between BMI and sleep duration. The secondary sex characteristics all originate from shared neuronal systems, with the hypothalamus as the integration point $(78,79)$. The hypothalamus also contains the sleep-wake and feeding circuits $(79,80)$, which are connected through the hypocretin- 1 hormone that regulates feeding and locomotor activity via the nucleus accumbens, as well as signals information on the light-dark cycle to the suprachiasmatic nucleus. Changes in hypothalamic functioning, such as disturbed hypocretin-1 signalling, might lead to disturbance of the circadian cycle and feeding behaviour, affecting energy balance and body composition over time $(78,79)$. For instance, children with short sleep duration show decreases in leptin concentrations, decreased insulin sensitivity and altered cortisol concentrations, all promoting lipogenesis (81-83). Thus, WesterterpPlantenga stated that changes in hypothalamic functioning, such as altered hypocretin-1 signalling, may explain the relationship between the changes in BMI and in sleep duration during puberty, via altered puberty onset, energy balance regulation and circadian rhythm. With respect to adolescents and adults, population statistics show that short sleep duration is a large and severe problem. It is estimated that 50-70 million Americans chronically suffer from a disorder of sleep and wakefulness, hindering daily functioning and adversely affecting health and longevity (84). The cumulative long-term effects of sleep loss and sleep disorders have been associated with a wide range of deleterious health consequences including an increased risk of hypertension, diabetes and obesity (84).

An inverse or a U-shaped relationship between sleep duration and BMI has been shown. Adults who slept $7.7 \mathrm{~h}$ had the lowest BMI; those with shorter and longer sleep duration had progressively higher BMI. Sleep insufficiency was associated with lower levels of leptin, suppressing appetite, and higher levels of ghrelin, stimulating appetite $(85,86)$. These findings suggest that a hormonally mediated increase in appetite may help to explain why short sleep is related to obesity. Mediating mechanisms may be effects of sleep deprivation on the sympathetic nervous system and/or hypothalamic hormones (86), which also influence appetite. Shorter sleep times were also associated with short- 
term impaired glucose tolerance (87); the effect resolved after restoring sleep to normal. Glucose clearance was $40 \%$ slower with sleep loss than with sleep recovery. Moreover, the association between sleep loss and diabetes or impaired glucose tolerance may also mediate the relationship between sleep loss and cardiovascular morbidity and mortality (84).

A further focus of the conference was on the lessons that come from comparative physiology and ecology studies. Klaas Westerterp and John Speakmann (88) have compared physical AEE levels in modern Western societies with those from third world countries and wild terrestrial mammals while taking into account both body size and temperature effects (88). Daily energy expenditures of individuals from most rural communities were on the expected line determined by gender, age and body mass for individuals in Western societies. The predicted energy expenditure from an equation derived from wild terrestrial mammals for a modern human of $78.6 \mathrm{~kg}$ was $9.2 \mathrm{MJ} \mathrm{d}^{-1}$. The actual expenditure across all the Maastricht data was 11.2 $\mathrm{MJ} \mathrm{d}^{-1}$, not lower than the prediction. Thus, based on this analysis, physical activity energy expenditure of modern man has not changed in recent times and matches energy expenditures of wild mammals (88). Ambient temperature also affects energy expenditure and, potentially, energy balance when a subject cannot stay in the thermoneutral zone where body temperature can be maintained by changing heat loss. The earliest civilizations developed in climatic regions close to thermoneutrality. Subsequently, new areas could be inhabited by wearing clothing and sheltering for extreme sunshine in daytime or low temperatures overnight. The next developments were heating systems from open fires to air conditioning. Man lives mainly in a thermoneutral environment. The predicted energy expenditure from an equation for wild mammals as presented above was derived for a typical room temperature of $20^{\circ} \mathrm{C}(88)$.

Stephen Simpson reviewed their approach to the behavioural strategies of animals in their nutritional environment. Simpson and Raubenheimer (89) developed a unifying framework that represents the multiple nutritional needs of the animal, the nutritional environment, the behavioural strategies of the animal when faced with that environment, and the associated performance and evolutionary consequences for the animal of these behavioural and physiological responses. This integrative modelling framework, called the geometric framework (GF), was devised and tested using insects but has since been applied to a wide range of organisms, from slime moulds to humans, and problems, ranging from aquaculture and conservation biology to the dietary causes of human obesity and ageing (89).

The GF has been used to show that dietary macronutrient balance plays a critical role in biological processes including growth, development, reproduction, ageing, immunity, and the susceptibility to both non-communicable and infectious diseases. Experimental data indicate that most animal species, including humans, have a separate protein appetite $(89,90)$. Moreover, it is suggested that humans when faced with imbalanced diets prioritize the absolute intake of protein to a 'target' level at the expense of regulating fat and carbohydrate intake $(91,92)$. Such 'protein leverage' has been demonstrated in other species, including non-human primates, pigs, rodents, birds, fish and insects (89), when the percentage of protein in the diet is lowered, total energy intake increases in an effort to maintain constant protein intake. The consequence is that dilution of protein in the diet by fat and/or carbohydrate encourages overconsumption of total energy, which in turn predisposes towards obesity and insulin resistance, causes loss of lean mass (93), and tips metabolic physiology into a vicious cycle towards accelerating obesity and metabolic disease $(79,80)$. Dilution of protein in the modern Western diet (94) is associated with various factors, including increased reliance on processed foods, economic pressures, and an ancestrally derived predilection by humans for the taste of fats and simple sugars $(89,95)$. Weigle et al. (96) showed a spontaneous reduction in energy intake upon a high protein diet in 19 subjects who were placed on an ad lib $30 \mathrm{EN} \%$ protein diet for 12 weeks. Energy intake was reduced to match the original satiety level, resulting in a decrease in body weight of $4.9 \mathrm{~kg}$ and fat mass by $3.7 \mathrm{~kg}$. In the meantime, several protein-diet studies have been undertaken, but these are confounded as they include a weight-loss and possibly a weight-maintenance program. These programs first induced body-weight changes and then used a protein diet to sustain satiety, energy expenditure and fat-free body mass at the original level (97). There is insufficient evidence to show a possible relationship between the protein leverage hypothesis and the use of protein diets for the management of obesity.

The changing function of the taste system was reviewed by Danielle Reed. A feature of the modern human diet is a decline in the concentrations of bitter-tasting chemicals in foods, a challenge for curious early humans foraging in jungles or savannas, because plant food (while plentiful) is also often poisonous (98). To reduce the risk of accidental poisoning, humans use their sense of taste, especially bitter perception. Bitter chemicals are produced by plants as secondary compounds that provide defence strategies against being eaten and, as such, they are often toxic, even after the consumption of only a few mouthfuls. To capitalize on an easily obtained food source, plants, humans devised strategies to remove or reduce their toxins, which in turn improved their taste $(99,100)$. Nonetheless, person-toperson differences in bitter perception arise (in part) because of genetic variation in the associated sensory receptors, e.g. (101). These genetic differences may have served 
a purpose in evolution when tradeoffs between poison detection and eating bitter famine foods were important for survival but now that the food supply is safer, heightened bitter sensitivity may create problems if it leads to the avoidance of healthful plant foods like vegetables (102). One of the mysteries of taste and evolution is why some bitter foods and drinks are liked even when the bitter taste itself is not. Coffee and tea contain several bitter compounds, the most familiar being caffeine and epicatechin. Alcohol, which is bitter to most people, is therefore often consumed with additives such as flavours or sweet solutions. The bitter compounds in these drinks may be pharmacologically rewarding; for instance, the stimulant effects of caffeine in coffee may help make the bitterness more tolerable, perhaps even liked, but at least socially wanted (103). The bitterness of ethanol may be a small detraction in the face of larger post-ingestion rewards (104). Often bitter beverages are shared with friends and family, and there may be social rewards as well as pharmacological ones for the ingestion of bitter-tasting beverages. Social conditioning is well understood in animal models of food preference learning (105) but is often overlooked as a potent force in human food intake (106). Genetic variation in taste perception is rarely studied in a social context, although mothers who are genetically insensitive to some bitter compounds report that their children are more emotional if the child is genetically bitter sensitive (107). If bitterness conveys a warning, sweet taste serves as a beacon for consumption and as an indicator of food desirability (108). Sweet is close to universally liked among humans (109). Sweet liking is present at birth (109) and most intense in children and young adults (99), perhaps as a signal of safe calories for growth (110). In addition to the effect of development on sweet preference, not everyone likes sweet equally, especially at very high concentrations. Differences among people in peripheral sensitivity to sweetness are due (in part) to genetic variants in the sweet receptor (111). Taken together, Reed showed that the function of the ability for taste perception has changed, from being used for detection of poison and energy, to being used as an element in social drinks, whose appreciation despite a negative taste needs to be learned, in order to be accepted by one's peers.

\section{Discussion}

The conference presentations emphasized that lifestyle and environmental insults operate against a genetic, epigenetic and evolutionary template. Obesity-related risks are lipotoxicity and metabolic problems (34-36) caused by exceeding the health boundaries of gene-environment flexibility $(4-15,112)$. Overall, there were several lessons from evolution and the environment that could be drawn from this meeting.
Lesson 1. Although it is often stated that the rise in obesity over the past 50 years cannot be caused by genetic factors because they could not have changed in such a short time, it is clear that the function of our genome can be changed on this timescale by two important factors. The first is epigenetic programming during our early lives. Perinatal metabolic programming for obesity by which epigenetic changes are induced by a Western diet was underscored (46). In animal models, this has been shown to result in metabolically efficient pups, contributing to the perpetuation of obesity throughout generations, as advocated by McLean (46). The second factor, which was brought up during the final discussion, is assortative mating. Assortative mating (the phenomenon of obese people mating preferentially with other obese people) clearly promotes the development of obesity in offspring that are derived from pairings of obese partners (113-116). The children of obese parents may be at greater risk for development of obesity because of two factors. The lifestyle choices of the children may be conditioned by the lifestyle choices of the parents, or the children may be more likely to be exposed to a greater number of risk alleles because of the genetic make-up of their parents. The evidence strongly suggests that this is a genetic (or potentially epigenetic) effect because the same risks of developing obesity are not present in the offspring that are raised by obese adoptive parents. It is likely that assortative mating has increased since the 1940s for two reasons. First, people now get married and have children at older ages, and second, people now get obese at younger ages. So it is now possible to assortatively mate for obesity when in the past this was probably impossible because people married and had children before it was evident who was going to become obese. Calculations suggest that the shift in assortative mating may have increased the prevalence of obesity by around $5 \%$ (113). Thus, this effect may contribute to, but has not completely caused, the epidemic. In the future, this effect may slow down because of possible infertility effects (117), but at present the impact of assortative mating on obesity prevalence is unambiguously positive. Alternatively, the effect of assortative mating may become magnified in the future as the offspring themselves from assortative matings assortatively mate. This would magnify the exposure to 'at risk' recessive alleles because such alleles would become concentrated among the offspring of successive assortative matings. This might lead to a form of 'super obesity' in individuals exposed to such concentrations of alleles. These effects may in fact prove to be more important than the classical genetic effects as the genome-wide association studies have only managed to identify genetic variants that underpin a tiny fraction of the total variation in BMI (8-11). Yet we know from classical twin and family studies that the total variation attributable to 'genetic' factors is much greater than this $(4-6,14,15)$. On the other hand, 
the brighter news is that we may not be at the mercy of these genetic and epigenetic effects. It may be possible to overcome our genetic destiny by specific lifestyle choices (7,65-74).

Lesson 2. We evolved in an environment that is very different from that we currently inhabit. We have changed our environment so that many adaptations to our past environment may be inappropriate in our modern world. These include our perception of food tastes, which previously guided us towards consumption of rare but advantageous foods, via macronutrient selection to achieve specific life history aims such as reproduction, to our ability to cope with the variations in food supply on a short timescale (98-111,118,119). A major problem is that these hardwired adaptive systems are less able to cope with a situation where such 'advantageous' foods are no longer rare, where novel macronutrient combinations are available that did not exist in prehistory, and where food is continuously available. Moreover, our environment nowadays contains many chemicals that we never encountered previously (5358). Evolution leaves us ill equipped to deal with such environmental insults.

Lesson 3: Humans develop over a particularly long time frame compared to most animals. We are constantly changing during this developmental period and indeed through the rest of our lives. Factors that are important at some stages of our development are less important at other stages. The dependencies of different factors on the stage of our lives at which they are studied probably explain many of the inconsistencies in the literature regarding the roles of different attributes on the etiology of obesity. For example, the role of the at-risk allele of the FTO gene $(10,31)$ wanes during puberty (76), and during the first half of our lives we accumulate muscle, but during the second part of our lives we lose it (66-68). Changes in muscle function with age and social factors associated with 'growing up' may underpin changes in physical activity, and hence energy balance with age (66). This developmental dimension of energy balance requires greater attention. We should avoid e.g. statements of the form ' $\mathrm{X}$ causes obesity' but rather make more qualified statements that ' $\mathrm{X}$ causes obesity at $\mathrm{Y}$ stage of life'. In addition, unforeseen changes may also cause social insecurity, implying sensing a future risk of food shortage, involving adaptation of the appetite regulation to serve both the current and future needs (120). When the social insecurity persists and the shortage of food never happens, obesity develops. This theory is compatible with observations of an inverse relation between social class and obesity, and of psychosocial disadvantaged conditions (121-126), but is inconsistent with the observation that the association with social class in developing countries is the reverse - the most socially secure and wealthy are the obese ones. In summary, the rise in obesity over the past 50 years cannot be caused by genetic factors because our genome could not change in such a short time. However, the function of our genome could be changed on this timescale by epigenetic programming and assortative mating. Second, we evolved in an environment that is very different from that we currently inhabit. We have changed our environment so that many adaptations to our past environment such as our perception of food tastes, and being evolutionary ill equipped with environmental insults like the many chemicals that previously we never encountered. Third, humans are developing over a particularly long time frame compared to most animals; we are constantly changing during this developmental period and through the rest of our lives. Factors that are important at some stages of our development are less important at other stages. In conclusion, the complex genetic and environmental interaction underlying the imbalance of energy intake and expenditure includes faster genome changes than had been assumed until now, continuous changes during our development and through the rest of our lives, and new environmental changes we have not been adapted to. This probably can only be fully appreciated by setting the data into the context of our evolutionary history.

\section{Conflict of interest statement}

None.

\section{Acknowledgements}

IASO, especially Prof. David York and Dr. Chris Trimmer, is gracefully acknowledged for offering the opportunity for the 9th Stock Conference. Contributions of each author are indicated in the text.

\section{References}

1. Huneault L, Mathieu MÈ, Tremblay A. Globalization and modernization: an obesogenic combination. Obes Rev 2011; 12: e64e72.

2. Lyznicki JM, Young DC, Riggs JA, Davis RM, Council on Scientific Affairs, American Medical Association. Obesity: assessment and management in primary care. Am Fam Physician 2001; 63: 2185-2196.

3. Ravussin E, Valencia ME, Esparza J, Bennett PH, Schulz O. Effects of a traditional lifestyle on obesity in Pima Indians. Diabetes Care 1994; 17: 1067-1074.

4. Bouchard C, Tremblay A, Despres JP et al. The response to long-term overfeeding in identical twins. N Engl J Med 1990; 322: $1477-1482$

5. Bouchard C, Tremblay A, Despres JP et al. The response to exercise with constant energy intake in identical twins. Obes Res 1994; 2: 400-410.

6. Hainer V, Stunkard AJ, Kunesova M, Parizkova J, Stich V, Allison DB. Intrapair resemblance in very low calorie diet-induced weight loss in female obese identical twins. Int J Obes Relat Metab Disord 2000; 24: 1051-1057. 
7. Hagberg JM, Rankinen T, Loos RJF et al. Advances in exercise, fitness, and performance genomics in 2010. Medicine and Science in Sports and Exercise 2011; 43: 743-752.

8. Kilpelainen TO. Physical activity attenuates the influence of FTO variants on obesity risk; a meta-analysis of 218,166 adults and 19,268 children. PLoS Med 2011; 8: e1001116.

9. Bell CG, Finer S, Lindgren CM et al. Integrated genetic and epigenetic analysis identifies haplotype-specific methylation in the FTO type 2 diabetes and obesity susceptibility locus. PLOS ONE 2010; 5: e14040.

10. Almen MS, Jacobsson JA, Moschonis G et al. Genome wide analysis reveals association of a FTO gene variant with epigenetic changes. Genomics 2012; 99: 132-137.

11. Li S, Zhao JH, Luan J et al. Physical activity attenuates the genetic predisposition to obesity in 20,000 men and women from EPIC-Norfolk prospective population study. PLoS Med 2010; 7: e1000332.

12. Westerterp KR. Energy metabolism and body composition; general principles. Eur Respir Mon 2003; 24: 1-10.

13. Snitker S, Tataranni PA, Ravussin E. Spontaneous physical activity in a respiratory chamber is correlated to habitual physical activity. Int J Obes 2001; 25: 1481-1486.

14. Westerterp KR, Kester ADM. Physical activity in confined conditions as an indicator of free-living physical activity. Obes Res 2003; 11: 865-868.

15. Joosen AMCP, Gielen M, Vlietinck R, Westerterp KR. Genetic analysis of physical activity in twins. Am J Clin Nutr 2005; 82: 1253-1259.

16. Edholm OG, Fletcher JG, Widdowson EM, McCance RA. The energy expenditure and food intake of individual men. $\mathrm{Br} J \mathrm{Nutr}$ 1955; 9: 286-300.

17. Blundell JE, Lawton CL, Cotton JR, Macdiarmid JI. Control of human appetite: implications for the intake of dietary fat. Annu Rev Nutr 1996; 16: 285-319. Review.

18. Lemmens SG, Martens EA, Kester AD, Westerterp-Plantenga MS. Changes in gut hormone and glucose concentrations in relation to hunger and fullness. Am J Clin Nutr 2011; 94: 717725 .

19. Adam TC, Westerterp-Plantenga MS. Glucagon-like peptide-1 release and satiety after a nutrient challenge in normal-weight and obese subjects. Br J Nutr 2005; 93: 845-851.

20. Adam TC, Jocken J, Westerterp-Plantenga MS. Decreased glucagon-like peptide 1 release after weight loss in overweight/ obese subjects. Obes Res 2005; 13: 710-716.

21. Hursel R, Rutters F, Gonnissen HK, Martens EA, WesterterpPlantenga MS. Effects of sleep fragmentation in healthy men on energy expenditure, substrate oxidation, physical activity, and exhaustion measured over $48 \mathrm{~h}$ in a respiratory chamber. Am J Clin Nutr 2011; 94: 804-808.

22. Rutters F, Gonnissen HK, Hursel R, Lemmens SG, Martens EA, Westerterp-Plantenga MS. Distinct associations between energy balance and the sleep characteristics slow wave sleep and rapid eye movement sleep. Int J Obes 2012; doi: 10.1038/ ijo.2011.250.

23. Westerterp-Plantenga MS, van Marken Lichtenbelt WD, Cilissen C, Top S. Energy metabolism in women during short exposure to the thermoneutral zone. Physiol Behav 2002; 75: 227-235. 24. Westerterp-Plantenga MS, van Marken Lichtenbelt WD, Strobbe H, Schrauwen P. Energy metabolism in humans at a lowered ambient temperature. Eur J Clin Nutr 2002; 56: 288-296. 25. Westerterp-Plantenga MS, Westerterp KR, Rubbens M, Verwegen CR, Richelet JP, Gardette B. Appetite at 'high altitude' [Operation Everest III (Comex-'97)]: a simulated ascent of Mount Everest. J Appl Physiol 1999; 87: 391-399.
26. Rutters F, Nieuwenhuizen AG, Lemmens SG, Born JM, Westerterp-Plantenga MS. Acute stress-related changes in eating in the absence of hunger. Obesity (Silver Spring) 2009; 17: 7277.

27. Lemmens SG, Rutters F, Born JM, Westerterp-Plantenga MS. Stress augments food 'wanting' and energy intake in visceral overweight subjects in the absence of hunger. Physiol Behav 2011; 103 : 157-163.

28. Born JM, Lemmens SG, Martens MJ, Formisano E, Goebel R, Westerterp-Plantenga MS. Differences between liking and wanting signals in the human brain and relations with cognitive dietary restraint and body mass index. Am J Clin Nutr 2011; 94: 392403.

29. Born JM, Lemmens SG, Rutters F et al. Acute stress and food-related reward activation in the brain during food choice during eating in the absence of hunger. Int J Obes 2010; 34: 172-181.

30. den Hoed M, Smeets AJ, Veldhorst MA et al. SNP analyses of postprandial responses in (an)orexigenic hormones and feelings of hunger reveal long-term physiological adaptations to facilitate homeostasis. Int J Obes 2008; 32: 1790-1798.

31. den Hoed M, Westerterp-Plantenga MS, Bouwman FG, Mariman EC, Westerterp KR. Postprandial responses in hunger and satiety are associated with the rs9939609 single nucleotide polymorphism in FTO. Am J Clin Nutr 2009; 90: 1426-1432.

32. Arble DM, Bass J, Laposky AD, Vitaterna MH, Turek FW. Circadian timing of food intake contributes to weight gain. Obesity (Silver Spring) 2009; 17: 2100-2102.

33. Turek FW, Vitaterna MH. Molecular neurobiology of circadian rhythms. Handb Clin Neurol 2011; 99: 951-961.

34. Sørensen TI. Obesity defined as excess storage of inert triglycerides - do we need a paradigm shift? Obes Facts 2011; 4: 91-94. 35. Sørensen TI, Virtue S, Vidal-Puig A. Obesity as a clinical and public health problem: is there a need for a new definition based on lipotoxicity effects? Biochim Biophys Acta 2010; 1801: 400-404. Review.

36. Wulan SN, Westerterp KR, Plasqui G. Ethnic differences in body composition and the associated metabolic profile: a comparative study between Asians and Caucasians. Maturitas 2010; 65: 315-319.

37. Elphingstone JJ. The health of Australian Aborigines with no previous association with Europeans. Med J Aust 1971; 2: 293 301.

38. O'Dea K. Traditional diet and food preferences of Australian Aboriginal hunter-gatherers. Philos Trans R Soc Lond B Biol Sci 1991; 334: 233-241.

39. Levin BE. Metabolic imprinting: critical impact of the perinatal environment on the regulation of energy homeostasis. Philos Trans R Soc Lond B Biol Sci 2006; 361: 1107-1121.

40. Dyer JS, Rosenfeld CR. Metabolic imprinting by prenatal, perinatal, and postnatal overnutrition: a review. Semin Reprod Med 2011; 29: 266-276.

41. Gorski JN, Dunn-Meynell AA, Hartman TG, Levin BE. Postnatal environment overrides genetic and prenatal factors influencing offspring obesity and insulin resistance. Am J Physiol Regul Integr Comp Physiol 2006; 291: R768-R778.

42. Le Foll C, Irani BG, Magnan C, Dunn-Meynell A, Levin BE. Effects of maternal genotype and diet on offspring glucose and fatty acid-sensing ventromedial hypothalamic nucleus neurons. Am J Physiol Regul Integr Comp Physiol 2009; 297: R1351R1357.

43. Plagemann A. Perinatal programming and functional teratogenesis: impact on body weight regulation and obesity. Physiol Behav 2005; 86: 661-668. 
44. Tamashiro KL, Moran TH. Perinatal environment and its influences on metabolic programming of offspring. Physiol Behav 2010; 100: 560-566.

45. Tamashiro KL, Terrillion CE, Hyun J, Koenig JI, Moran TH. Prenatal stress or high-fat diet increases susceptibility to dietinduced obesity in rat offspring. Diabetes 2009; 58: 1116-1125. 46. Wahlig JL, Bales ES, Jackman MR, Johnson GC, McManaman JL, Maclean PS. Impact of high-fat diet and obesity on energy balance and fuel utilization during the metabolic challenge of lactation. Obesity (Silver Spring) 2012; 20: 65-75.

47. Patterson CM, Bouret SG, Dunn-Meynell AA, Levin BE. Three weeks of postweaning exercise in DIO rats produces prolonged increases in central leptin sensitivity and signaling. Am J Physiol Regul Integr Comp Physiol 2009; 296: R537-R548.

48. Patterson CM, Dunn-Meynell AA, Levin BE. Three weeks of early-onset exercise prolongs obesity resistance in DIO rats after exercise cessation. Am J Physiol Regul Integr Comp Physiol 2008; 294: R290-R301.

49. Amir LH, Donath S. A systematic review of maternal obesity and breastfeeding intention, initiation and duration. BMC Pregnancy Childbirth 2007; 7: 9 .

50. Mok E, Multon C, Piguel L et al. Decreased full breastfeeding, altered practices, perceptions, and infant weight change of prepregnant obese women: a need for extra support. Pediatrics 2008; 121: e1319-e1324.

51. Gluckman PD, Hanson MA. The developmental origins of the metabolic syndrome. Trends Endocrinol Metab 2004; 15: 183-187. 52. Heindel JJ, vom Saal FS. Role of nutrition and environmental endocrine disrupting chemicals during the perinatal period on the etiology of obesity. Mol Cell Endocrinol 2009; 304: 90-96.

53. Skakkebaek NE, Rajpert-De Meyts E, Main KM. Testicular dysgenesis syndrome: an increasingly common developmental disorder with environmental aspects. Hum Reprod 2001; 16: 972 978.

54. Tang-Péronard JL, Andersen HR, Jensen TK, Heitmann BL. Endocrine-disrupting chemicals and obesity development in humans: a review. Obes Rev 2011; 12: 622-636.

55. Newbold RR, Padilla-Banks E, Jefferson WN, Heindel JJ. Effects of endocrine disruptors on obesity. Int J Androl 2008; 31: 201-208.

56. vom Saal FS, Akingbemi BT, Belcher SM et al. Chapel Hill bisphenol A expert panel consensus statement: integration of mechanisms, effects in animals and potential to impact human health at current levels of exposure. Reprod Toxicol 2007; 24: 131-138.

57. Stahlhut RW, van Wijngaarden E, Dye TD, Cook S, Swan SH. Concentrations of urinary phthalate metabolites are associated with increased waist circumference and insulin resistance in adult U.S. males. Environ Health Perspect 2007; 115: 876-882.

58. Jensen AA, Leffers H. Emerging endocrine disrupters: perfluoroalkylated substances. Int J Androl 2008; 31: 161-169.

59. Begley TH. Migration of fluorochemical paper additives from food-contact paper into foods and food simulants. Food Addit Contam Part A 2008; 25: 384-390.

60. Lau C. Perfluoroalkyl acids: a review of monitoring and toxicological findings. Toxicol Sci 2007; 99: 366-394.

61. Halldorsson TI, Rytter D, Haug LS et al. Prenatal exposure to perfluorooctanoate and risk of overweight at 20 years of age: a prospective cohort study. Environ Health Perspect 2012; 120: 668-673.

62. Miyawaki J, Sakayama K, Kato $\mathrm{H}$ et al. Perinatal and postnatal exposure to bisphenol $\mathrm{A}$ increases adipose tissue mass and serum cholesterol level in mice. J Atheroscler Thromb 2007; 14: $245-252$
63. Lang IA, Galloway TS, Scarlett A et al. Association of urinary bisphenol A concentration with adults medical disorders and laboratory abnormalities in adults. JAMA 2008; 300: 1303-1310. 64. Hatch EE, Nelson JW, Qureshi MM et al. Association of urinary phthalate metabolite concentrations with body mass index and waist circumference: a cross-sectional study of NHANES data, 1999-2002. Environ Health 2008; 7: 27.

65. Butte NF, Ekelund U, Westerterp KR. Assessing physical activity using wearable monitors: measures of physical activity. Med Sci Sports Exerc 2012; 44: S5-S12.

66. Speakman JR, Westerterp KR. Associations between energy demands, physical activity and body composition in adult humans between 18 and 96 years of age. Am J Clin Nutr 2010; 92: 826-834. 67. Ekelund U, Aman J, Yngve A, Renman C, Westerterp K, Sjöström M. Physical activity but not energy expenditure is reduced in obese adolescents: a case-control study. Am J Clin Nutr 2002; 76: 935-941.

68. Westerterp KR, Plasqui G. Physically active lifestyle does not decrease the risk of fattening. PLoS ONE 2009; 4: e4745.

69. Sallis JF. Age-related decline in physical activity: a synthesis of human and animal studies. Med Sci Sports Exerc 2000; 32: 1598 1600 .

70. Malina RM. Promoting physical activity in children and adolescents: a review. Clin J Sport Med 2008; 18: 549-550.

71. Teran-Garcia M, Rankinen T, Bouchard C. Genes, exercise, growth, and the sedentary, obese child. J Appl Physiol 2008; 105: 988-1001.

72. Eisenmann JC, Wickel EE. The biological basis of physical activity in children: revisited. Pediatr Exerc Sci 2009; 21: $257-$ 372.

73. Sherar LB, Cumming SP, Eisenmann JC, Baxter-Jones AD, Malina RM. Adolescent biological maturity and physical activity: biology meets behavior. Pediatr Exerc Sci 2010; 22: 332-349.

74. Malina RM. Physical activity and fitness: pathways from childhood to adulthood. Am J Hum Biol 2001; 13: 162-172.

75. Rutters F, Gerver WJ, Nieuwenhuizen AG, Verhoef SP, Westerterp-Plantenga MS. Sleep duration and body-weight development during puberty in a Dutch children cohort. Int J Obes 2010; 34: 1508-1514.

76. Rutters F, Nieuwenhuizen AG, Bouwman F, Mariman E, Westerterp-Plantenga MS. Associations between a single nucleotide polymorphism of the FTO gene (rs9939609) and obesityrelated characteristics over time during puberty in a Dutch children cohort. I Clin Endocrinol Metab 2011; 96: E939-E942.

77. Rutters F, Nieuwenhuizen AG, Verhoef SP, Lemmens SG, Vogels N, Westerterp-Plantenga MS. The relationship between leptin, gonadotropic hormones, and body composition during puberty in a Dutch children cohort. Eur J Endocrinol 2009; 160: 973-978.

78. Adamantidis A, de Lecea L. Sleep and metabolism: shared circuits, new connections. Trends Endocrinol Metab 2008; 19: 362-370.

79. Vanitallie TB. Sleep and energy balance: interactive homeostatic systems. Metabolism 2006; 55 (10 Suppl. 2): S30-S35. 80. Plazzi G, Parmeggiani A, Mignot E et al. Narcolepsycataplexy associated with precocious puberty. Neurology 2006; 66: $1577-1579$.

81. Flint J, Kothare SV, Zihlif M et al. Association between inadequate sleep and insulin resistance in obese children. $J$ Pediatr 2007; 150: 364-369.

82. Hitze B, Bosy-Westphal A, Bielfeldt F et al. Determinants and impact of sleep duration in children and adolescents: data of the Kiel Obesity Prevention Study. Eur I Clin Nutr 2009; 63: 739746. 
83. Raikkonen K, Matthews KA, Pesonen AK et al. Poor sleep and altered hypothalamic-pituitary-adrenocortical and sympathoadrenal-medullary system activity in children. J Clin Endocrinol Metab 2010; 95: 2254-2261.

84. Colten HR, Altevogt BM (eds). Sleep Disorders and Sleep Deprivation: An Unmet Public Health Problem. National Academies Press: Washington, DC, 2006.

85. Taheri S, Lin L, Austin D et al. Short sleep duration is associated with reduced leptin, elevated ghrelin, and increased body mass index. PLoS Med 2004; 1: 210-217.

86. Spiegel K, Tasali E, Penev P, Van Cauter E. Brief communication: sleep curtailment in healthy young men is associated with decreased leptin levels, elevated ghrelin levels, and increased hunger and appetite. Ann Intern Med 2004; 141: 846-850.

87. Spiegel K, Leproult R, Van Cauter E. Impact of sleep debt on metabolic and endocrine function. Lancet 1999; 354: 14351439 .

88. Westerterp KR, Speakman JR. Physical activity energy expenditure has not declined since the 1980s and matches energy expenditures of wild mammals. Int J Obes 2008; 32: 12561263.

89. Simpson SJ, Raubenheimer D. The Nature of Nutrition: A Unifying Framework from Animal Adaptation to Human Obesity. Princeton University Press: Princeton, NJ, 2012.

90. Griffioen-Roose S, Mars M, Siebelink E, Finlayson G, Tomé D, de Graaf C. Protein status elicits compensatory changes in food intake and food preferences. Am J Clin Nutr 2012; 95: 32-38.

91. Simpon SJ, Raubenheimer D. Obesity: the protein leverage hypothesis. Obes Rev 2005; 6: 133-142.

92. Gosby AK, Conigrave AD, Lau NS et al. Testing protein leverage in lean humans: a randomised controlled experimental study. PLOS ONE 2011; 6: e25929.

93. Bray GA, Smith SR, Jonge L et al. Effect of dietary protein content on weight gain, energy expenditure, and body composition during overeating: a randomized controlled trial. JAMA 2012; 307: 47-55.

94. Austin GL, Ogden LG, Hill JO. Trends in carbohydrate, fat, and protein intakes and association with energy intakes in normalweight, overweight, and obese individuals: 1971-2006. Am J Clin Nutr 2011; 93: 836-843.

95. Brooks RC, Simpson SJ, Raubenheimer D. The price of protein: combining evolutionary and economic analysis to understand excessive energy consumption. Obes Rev 2010; 11: 887894.

96. Weigle DS, Breen PA, Matthys CC et al. A high-protein diet induces sustained reductions in appetite, ad libitum caloric intake, and body weight despite compensatory changes in diurnal plasma leptin and ghrelin concentrations. Am J Clin Nutr 2005; 82: $41-48$.

97. Westerterp-Plantenga MS, Nieuwenhuizen A, Tomé D, Soenen S, Westerterp KR. Dietary protein, weight loss, and weight maintenance. Annu Rev Nutr 2009; 29: 21-41.

98. VanEtten C. Goitrogens. In: Liener IE (ed.). Toxic Constituents of Plant Foodstuffs. Food Science and Technology. Academic Press: New York, 1969, pp. 103-142.

99. Drewnowski A, Gomez-Carneros C. Bitter taste, phytonutrients, and the consumer: a review. Am J Clin Nutr 2000; 72: 1424-1435.

100. Leopold AC, Ardrey R. Toxic substances in plants and the food habits of early man. Science 1972; 176: 512-514.

101. Bufe B, Breslin PA, Kuhn C et al. The molecular basis of individual differences in phenylthiocarbamide and propylthiouracil bitterness perception. Curr Biol 2005; 15: 322-327.
102. Sandell MA, Breslin PA. Variability in a taste-receptor gene determines whether we taste toxins in food. Curr Biol 2006; 16: R792-R794.

103. Yeomans MR, Durlach PJ, Tinley EM. Flavour liking and preference conditioned by caffeine in humans. Q J Exp Psychol 2005; 58: 47-58.

104. Bachmanov AA, Kiefer SW, Molina JC et al. Chemosensory factors influencing alcohol perception, preferences, and consumption. Alcohol Clin Exp Res 2003; 27: 220-231.

105. Galef BG Jr. Enduring social enhancement of rats' preferences for the palatable and the piquant. Appetite 1989; 13: 8192.

106. de Castro JM. Eating behavior: lessons from the real world of humans. Nutrition 2000; 16: 800-813.

107. Mennella JA, Pepino MY, Reed DR. Genetic and environmental determinants of bitter perception and sweet preferences. Pediatrics 2005; 115: e216-e222.

108. McDaniel AH, Reed DR. The human sweet tooth and its relationship to obesity. In: Berndanier CD, Moustaid-Moussa N (eds). Genomics and Proteomics in Nutrition. Marcel Dekker, Inc: New York, 2004, pp. 44-60.

109. Steiner JE, Glaser D, Hawilo ME, Berridge KC. Comparative expression of hedonic impact: affective reactions to taste by human infants and other primates. Neurosci Biobehav Rev 2001; 25: 53-74.

110. Coldwell SE, Oswald TK, Reed DR. A marker of growth differs between adolescents with high vs. low sugar preference. Physiol Behav 2009; 96: 574-580.

111. Fushan AA, Simons CT, Slack JP, Manichaikul A, Drayna D. Allelic polymorphism within the TAS1R3 promoter is associated with human taste sensitivity to sucrose. Curr Biol 2009; 19: 12881293.

112. Speakman JR, Levitsky DA, Allison DB et al. Set-points, settling points and some alternative models: theoretical options to understand how genes and environments combine to regulate body adiposity. Dis Model Mech 2011; 4: 733-745.

113. Speakman JR, Djafarian K, Stewart J, Jackson DM. Assortative mating for obesity. Am J Clin Nutr 2007; 86: 316323.

114. Hebebrand J, Wulftange $\mathrm{H}$, Goerg $\mathrm{T}$ et al. Epidemic obesity: are genetic factors involved via increased rates of assortative mating. Int J Obes Relat Metab Disord 2000; 24: $345-353$.

115. Fontaine KR, Robertson HT, Holst C et al. Is socioeconomic status of the rearing environment causally related to obesity in the offspring? PLOS ONE 2011; 6: e27692.

116. Ramlau-Hansen CH, Thulstrup AM, Nohr EA et al. Subfecundity in overweight and obese couples. Hum Reprod 2007; 22: 1634-1637.

117. Warbrick-Smith J, Behmer ST, Lee K-P, Raubenheimer D, Simpson SJ. Evolving resistance to obesity in an insect. Proc Natl Acad Sci U S A 2006; 103: 14045-14049.

118. Mintz SW. Sweetness and Power: The Place of Sugar in Modern History. Penguin Books: New York, 1986.

119. Desor JA, Beauchamp GK. Longitudinal changes in sweet preferences in humans. Physiol Behav 1987; 39: 639-641.

120. Sørensen TIA. Is obesity a healthy active accumulation of reserve energy in response to social insecurity read as an expected future lack of energy? Obes Facts 2012.

121. Sobal J, Stunkard AJ. Socioeconomic status and obesity: a review of the literature. Psychol Bull 1989; 105: 260-275.

122. Shrewsbury V, Wardle J. Socioeconomic status and adiposity in childhood: a systematic review of cross-sectional studies 19902005. Obesity (Silver Spring) 2008; 16: 275-284. 
123. Lissau I, Sørensen TI. Parental neglect during childhood and increased risk of obesity in young adulthood. Lancet 1994; 343: 324-327.

124. Offer A, Pechey R, Ulijaszek S. Obesity under affluence varies by welfare regimes: the effect of fast food, insecurity, and inequality. Econ Hum Biol 2010; 8: 297-308.
125. Vamosi M, Heitmann BL, Thinggaard M, Kyvik KO. Parental care in childhood and obesity in adulthood: a study among twins. Obesity (Silver Spring) 2011; 17: 1-6.

126. Stunkard AJ, Sørensen TI. Obesity and socioeconomic status - a complex relation. N Engl J Med 1993; 329: 10361037. 